\title{
The Bond Strength of Glass Fiber Reinforced Polymer (GFRP) Reinforcement with Monolith Concrete
}

\author{
Anis Rosyidah $^{\#}$, I Ketut Sucita ${ }^{\#}$, Fery Hidayat ${ }^{\#}$ \\ ${ }^{\#}$ Department of Civil Engineering, Politeknik Negeri Jakarta, Jl. Prof. GA. Siwabessy Kampus UI Depok, 16425, Indonesia \\ E-mail:anis.rosyidah@gmail.com; cita.sandi@gmail.com; fery.hidayat@gmail.com
}

\begin{abstract}
One of the considerations in selecting Glass Fiber Reinforced Polymer (GFRP) as a substitute for conventional reinforcement is its ability against corrosion makes it suitable for structures directly related to land, water, and corrosive areas. Regarding strength, GFRP which has high yield strength is very suitable as a reinforcement to hold the shear force. Similarly, as with steel bar, GFRP reinforcement is used as a composite material of reinforced concrete; therefore, it is worth to know the grade of the bond strength. The bond strength is one of the crucial factors to have a good interaction between GFRP and concrete in holding workloads on structures so that the study is conducted to get the grade of the bond strength of GFRP reinforcement with monolith concrete cast. The experiment is using the pullout test with a cube specimens, sized $250 \mathrm{~mm} \times 250 \mathrm{~mm} \times 250 \mathrm{~mm}$ and GFRP bar sized $25 \mathrm{~mm}$ diameters. Bond strength of GFRP reinforcement will then be close compared to the bond strength of BJTS40 deform rebar sized $25 \mathrm{~mm}$ diameters. The concrete used in this study has about $\mathrm{f}^{\prime} \mathrm{c} 100 \mathrm{MPa}$. The test results indicate the grade of bond strength of GFRP reinforcement with concrete reaches 6.54 MPa and the bond strength of steel bar with concrete reaches 8.22 MPa. The degree of bond strength of GFRP reinforcement is smaller $79.56 \%$ than the bond strength of the steel reinforcement. What the failure happened on all test objects is the mode of splitting failure.
\end{abstract}

Keywords — bond strength, pull out, GFRP, monolith concrete.[1]

\section{INTRODUCTION}

Reinforced concrete is a composite material for building structural elements between concrete and steel reinforcement that interact in holding the working loads [1],[2],[3]. Steel bars often used in reinforced concrete. Steel which is very easy to get and relatively cheap is still a favorite material for construction work in bearing the tensile strength, yet steel still has weaknesses. One of the weaknesses is that it is straightforward to get corrosion and weighs ponderosity so that the dimension of the structure of the building becomes more massive and cumbersome due to the weight of itself [4], [5], [2]. As the construction technology grows well, steel bars have replaced by fiber reinforcement made of fiber and resins [3]. Fiber Reinforced Polymer (FRP) reinforcement, which is an innovation in structure design is qualified because FRP reinforcement is lightweight, not corrosive, and has high strength [3],[6],[4],[5]. FRP is composed of resin and fiber, the resin comprising polymer has poor resistance to fire. The elements contained in polymers such as carbon, hydrogen, and nitrogen are all combustible materials. Besides that, the disadvantage of FRP is more expensive than steel. Nevertheless, FRP remains a choice because of its resistance to corrosion. Several buildings which use FRP reinforcement are Kitakyushu Bridge (Japan), Yamanaka Bridge (Japan), Bromley South Bride (UK), Kansas Detour Bridge (USA), and Tunnel structural of MRT Jakarta.

The bond strength becomes one of the substantial factors to create a good interaction between FRP reinforcement and concrete in holding workloads on structures [4], [5], [6]. The loss of bond strength between the concrete and the bars of the structure leads to a failure of the component. GFRP bars surface wrapped with a fiber strand to form indentations along the rebar to enhance the bonding strength (Fig. 1) [7]. The pullout test is one kind of testing methods to know the bond strength between concrete and bars [8], [9], [10].

The bond strength is the shear stress on the concrete surface; there is a force of transfer from the reinforcement to the surrounding concrete. This bonding is continued efficiently and allows two different materials to form a composite structure. The bond strength between the reinforcement and the concrete is a particular composition of the adhesion, friction and interlocking forces of the irregular reinforcing surface. The rough interface can increase the adhesion capacity due to locking of bars reinforcement and concrete around it. The tensile strength held by the reinforcement transferred to the concrete through the thread. 
Low bonding can lead to slippage so that the adhesion reduced. The deformation between reinforcement and the surrounding concrete is held only by friction along the slip area.

\section{MATERIAL AND METHOD}

This study presents the bond strength and mode of failure of glass fiber-reinforced polymer bar in high-performance concrete using direct pullout, then compare with deform reinforcement.

GFRP bars used in this experiment observed in Fig. 1. The material properties presented in Table I.

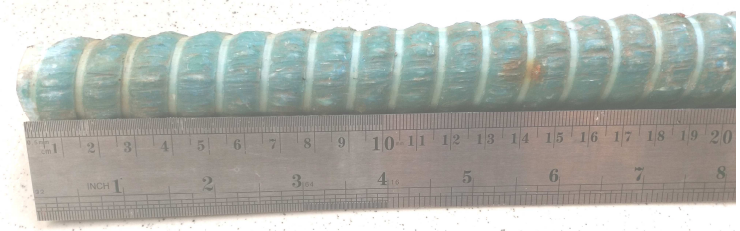

Fig. 1 GFRP bars

Table I. Material Properties of GFRP

\begin{tabular}{|c|l|c|}
\hline No. & Item & Value \\
\hline 1. & Specific weight $\left(\mathrm{g} / \mathrm{cm}^{3}\right)$ & 2.2 \\
\hline 2. & Tensile strength $\left(\mathrm{N} / \mathrm{mm}^{2}\right)$ & $800-1000$ \\
\hline 3. & Tensile E-Modulus $\left(\mathrm{N} / \mathrm{mm}^{2}\right)$ & $40,000-60,000$ \\
\hline 4. & Ultimate strain $(\%)$ & $1.5-2.5$ \\
\hline
\end{tabular}

(Source: Firep Rebar Japan)

The specimens used were GFRP deformed bars cast monolithically with cubes concrete with a size of $250 \mathrm{~mm} \mathrm{x}$ $250 \mathrm{~mm} \times 250 \mathrm{~mm}$ (Fig. 2 and 3) [11]. The bars diameter size is $25 \mathrm{~mm}$ with f'c $80 \mathrm{MPa}$ ready-mix concrete. The result of counting the bond strength of GFRP reinforcement compares to the bond strength of deform steel bars with the same size and diameter. Before pullout testing was done on GFRP bar, the reinforcement should give FRP carbon grips at each side (Fig. 4 and 5) [12]. FRP carbon grip here was five (5) days old when it was formed to be cubed and be sharpened to fit the section of Universal Testing Machine (UTM) (Fig. 6) [13].

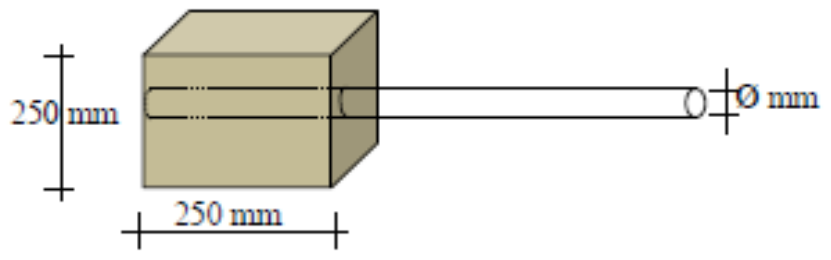

Fig. 2 Specimen of Pullout Test

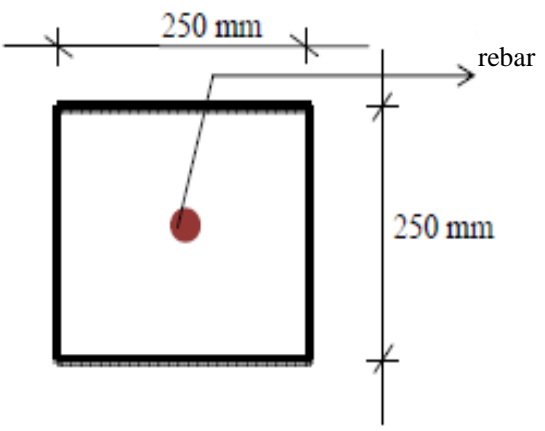

Fig. 3 Top View of Specimen

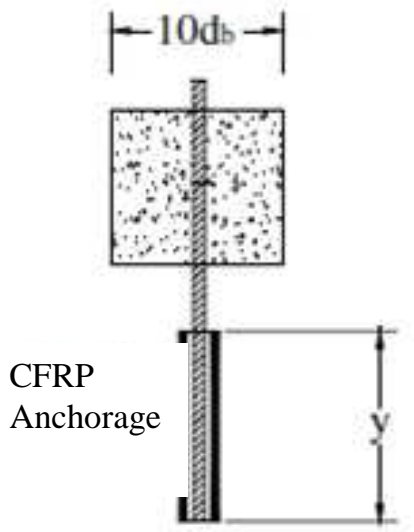

Fig. 4 GFRP Grip at Each Side [12]

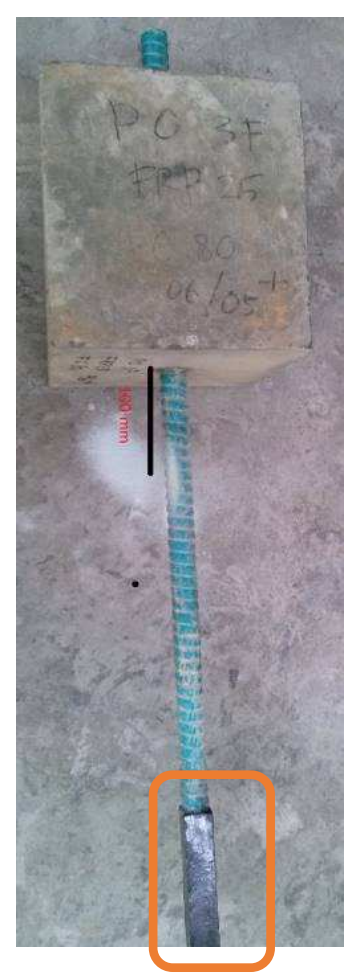

Fig. 5 Grip of GFRP Specimen 


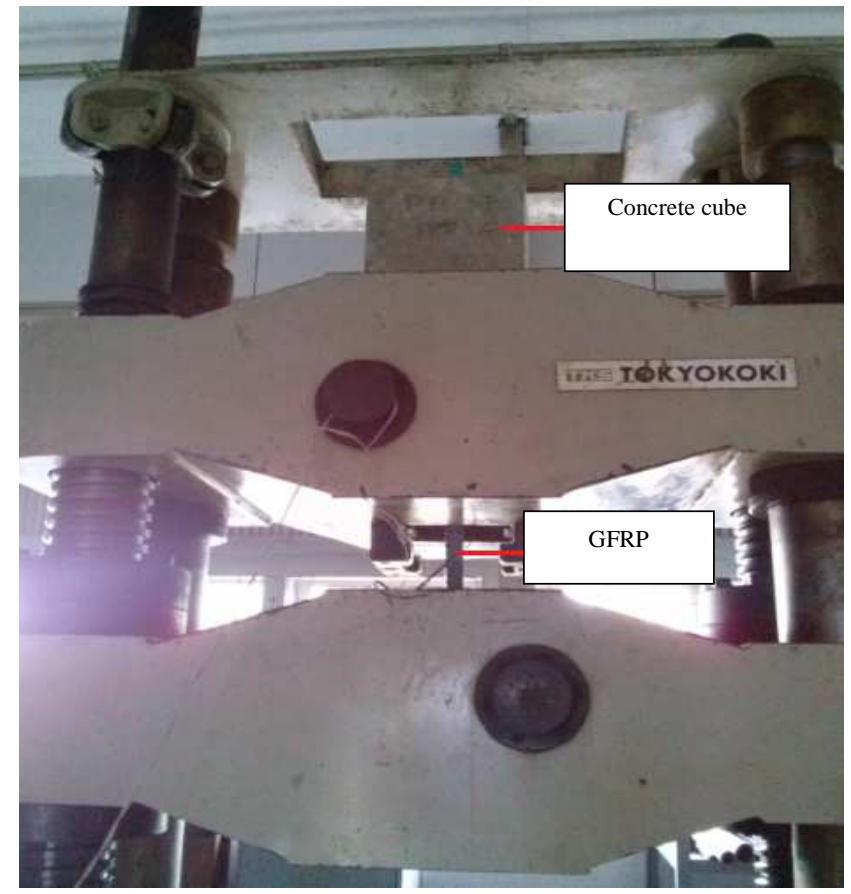

Fig. 6 Set up the Pullout Test

\section{RESULTS AND DISCUSSION}

\section{A. The Unit Weight of Steel Bars and GFRP bars}

The average unit weight analysis on specimens of steel bars and GFRP reinforcement was $7611 \mathrm{~kg} / \mathrm{m} 3$ for steel bars and $2542 \mathrm{~kg} / \mathrm{m} 3$ for GFRP reinforcement (Fig. 7). The GFRP reinforcement unit weight was lighter than steel bars. The ratio of the density was that GFRP reinforcement 0.33 bigger than steel bars. That rate was similar with the result of the research conducted by Lesmana Alfred, et, all (2014) [14], GFRP reinforcement 0.2 bigger than steel bars.

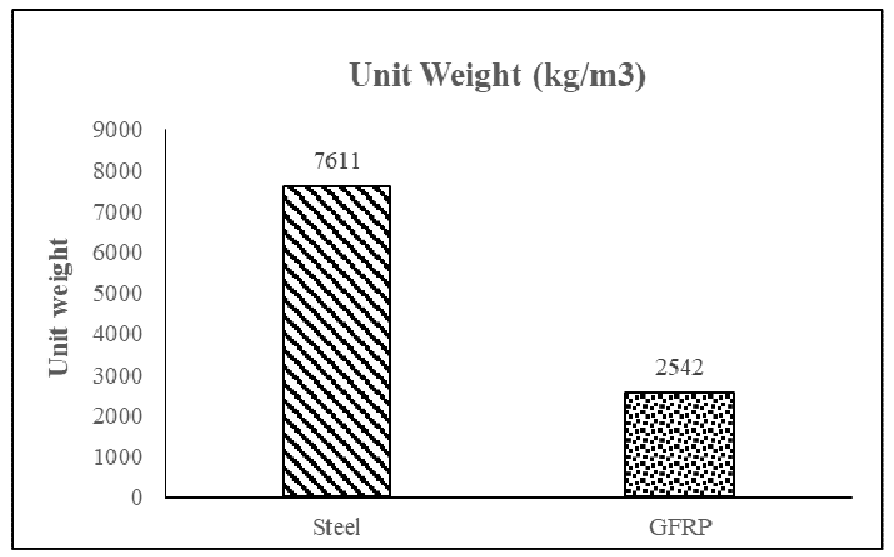

Fig. 7 Diagram of Unit Weight Comparison

\section{B. The Compressive Strength of Concrete}

The compressive strength tests on cylinder specimens, the result was $102.6 \mathrm{MPa}$ average score on 28 days old concretes. The average rating of the compressive strength was higher than the prediction which was $80 \mathrm{MPa}$. It was increasing to $128 \%$ from the compressive strength prediction. The compressive strength reaches $102.6 \mathrm{MPa}$; it means the concrete will have splitting stress around $0.57 \times \sqrt{ } 102,6=$
5,77 $\mathrm{MPa}$. The ratio of splitting stress was used to evaluate the actual ability in receiving pressure from the radial load. If the splitting stress exceeds, so the concrete will crack [15].

\section{The Tensile Strength of Steel Bars and GFRP bars}

The analysis of the tensile strength of steel bars and the tensile strength of GFRP reinforcement using ASTM D638 resulted in the yield stress on steel bars, but not on GFRP reinforcement. The yield stress of steel bars was 440.6 MPa. On the contrary, the ultimate stress was $610.8 \mathrm{MPa}$ on steel bars and $680.8 \mathrm{MPa}$ on GFRP reinforcement with 0.9 ratios as described in Fig. 8 [16].

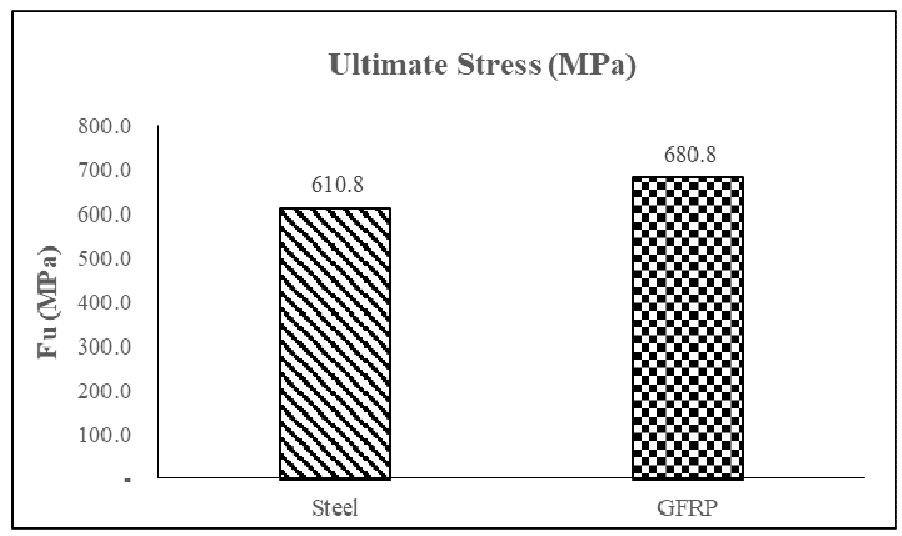

Fig. 8 Ultimate Stress Comparison

High GFRP reinforcement tensile strength is suitable for building structures which have massive tensile forces such as bending structures or tendons. However, the tensile stress of GFRP should be able to reach its maximum tensile strength of $1000 \mathrm{MPa}$.

The GFRP reinforcement tensile force $30 \%$ declined due to the weather which influenced resin quality. Resins used as the primary material in making this GFRP reinforcement. The strength of resin also decreased due to overheating; it occurred because resins placed outdoor. Fig. 9 and Fig. 10 below show the chart of strain-stress of steel bar and GFRP reinforcement.

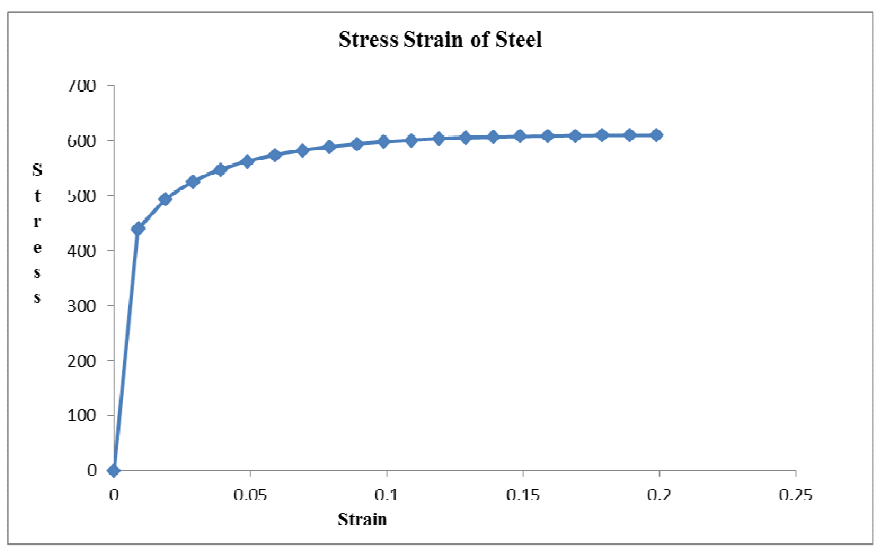

Fig. 9 Strain stress of Steel Bar

The tensile strength test results show more ductile steel reinforcement than GFRP. It is seen in Fig. 9 that steel reinforcement has a strain of hardening whereas GFRP in Fig.10 yield point and fracture occur at one point. 


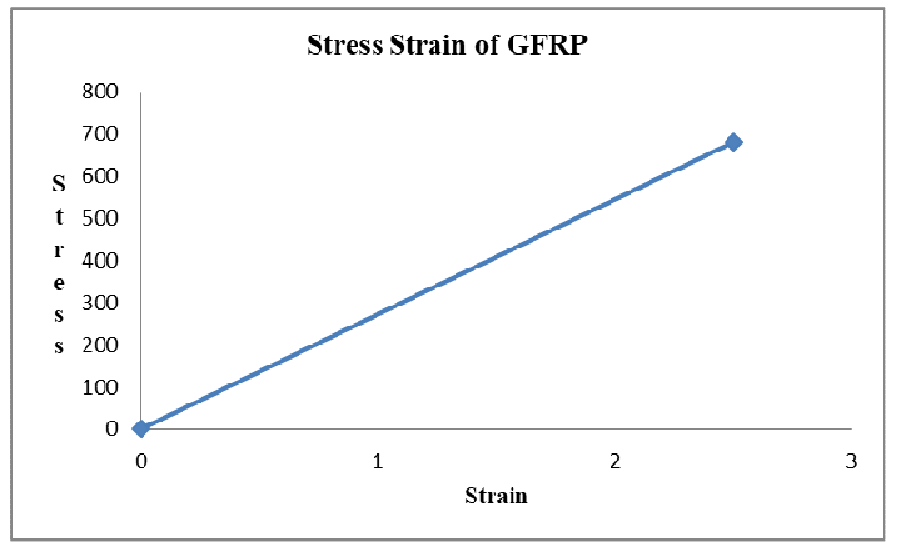

Fig. 10 Strain stress of GFRP Reinforcement

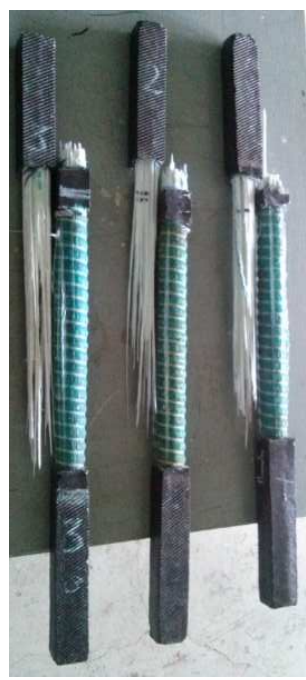

(a) GFRP bars

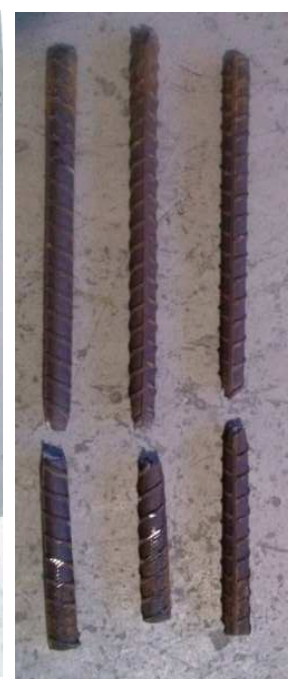

(b) Steel bars
Fig. 11 Fracture Pattern of Reinforcement

Figure 11 shows that the pattern of GFRP and steel reinforcement is different. The steel bars more ductile than GFRP bars.

\section{The Elasticity Modulus of Steel Bars and GFRP bars}

Based on the result, GFRP reinforcement had a lower modulus of elasticity than steel reinforcement with 0.15 ratio as Fig. 12.

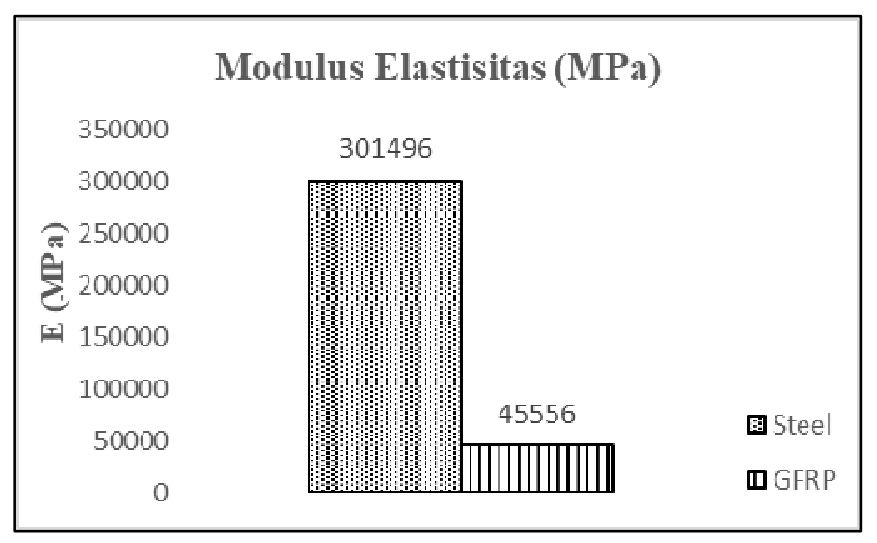

Fig. 12 Modulus of Elasticity Comparison
A low GFRP modulus of elasticity would cause the structure became more brittle so the rigid grade would increase. It is relevant to what Ahmad Azim Shukri et al. (2015) points out that stiff degree of FRP reinforcement concrete is higher than steel reinforcement [17].

\section{E. The Bond Strength}

The analysis results taken on pullout test, the result showed the average bond strength was $8.22 \mathrm{MPa}$ on steel reinforcement and 6.54 MPa on GFRP reinforcement as Fig. 13 shows below. The GFRP bond strength was $79.56 \%$ smaller than steel reinforcement. Ivan Holly, et, all (2016) also indicates that the GFRP bond strength is $55-90 \%$ lower than steel reinforcement [18].

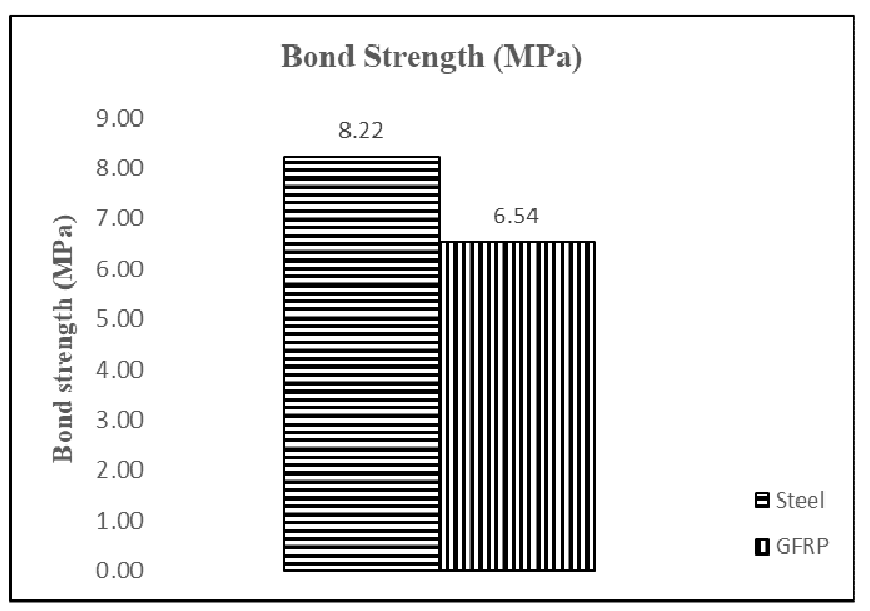

Fig. 13 Bond Strength Comparison on Steel and GFRP

Comparing the bond strength between concrete and steel reinforcement or concrete and GFRP reinforcement was not maximum. The concrete cracking and splitting before the yield strength and also tensile strength achieved, this failure is called Splitting failure (Fig. 14 and 15).
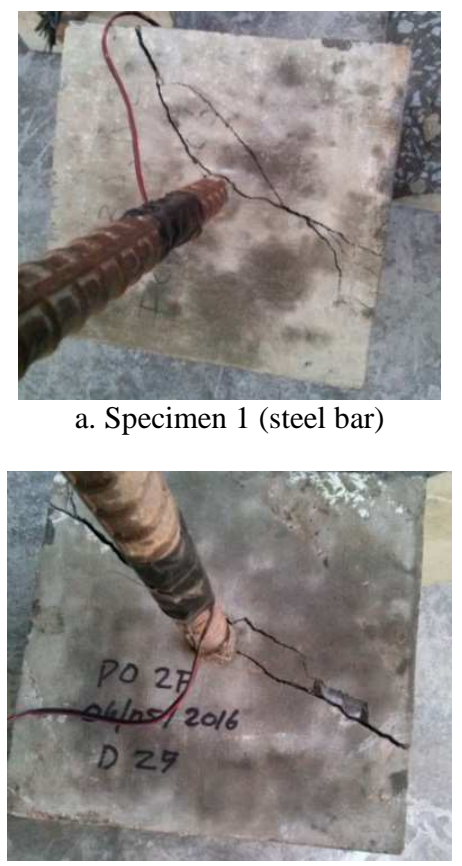

b. Specimen 2 (steel bar) 


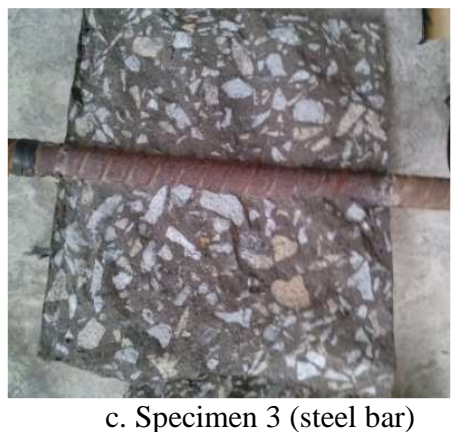

Fig. 14. The Failure Pattern of Steel Bars Specimen

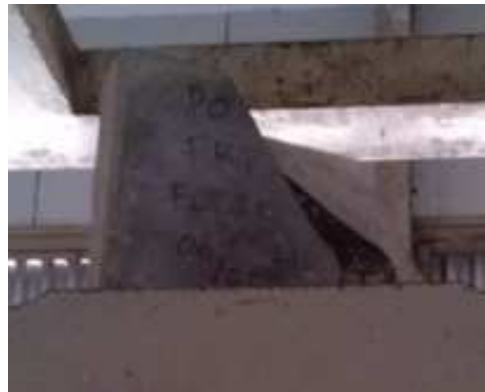

a. Specimen 1 (GFRP bar)

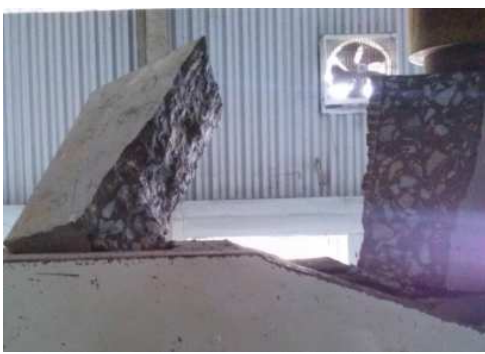

b. Specimen 2 (GFRP bar)

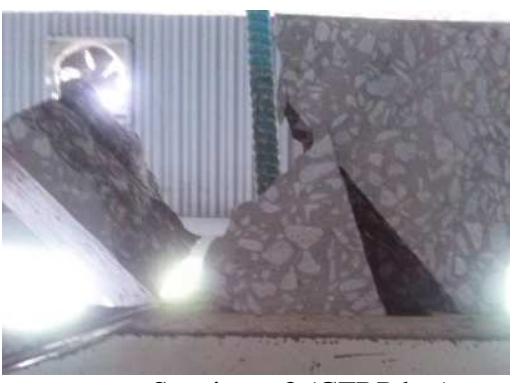

c. Specimen 3 (GFRP bar)

Fig. 15. The Failure Pattern of GFRP Bars Specimen

The concrete compressive which had 5.77 MPa split force could not hold the tensile strength which was more significant than its splitting effect [15]. The concrete which was forced by radial force would have tensile-split force. If the splitting force maximum exceeds so, it will cause splitting-crack.

The diameter of the reinforcement was big that cause the failure because the tensile reinforcement strength was much bigger than the bond strength, in consequence, the concrete became split-crack if the diameter of the reinforcement were too small then it would cause ultimate failure on the reinforcement because the bond strength was much higher than the ultimate strength. If the tensile reinforcement strength is much bigger than the bond strength, it will cause split-crack immediately [15]. The slip of pull out test specimens was more than critical bond strength as shown in Fig. 16 and 17.

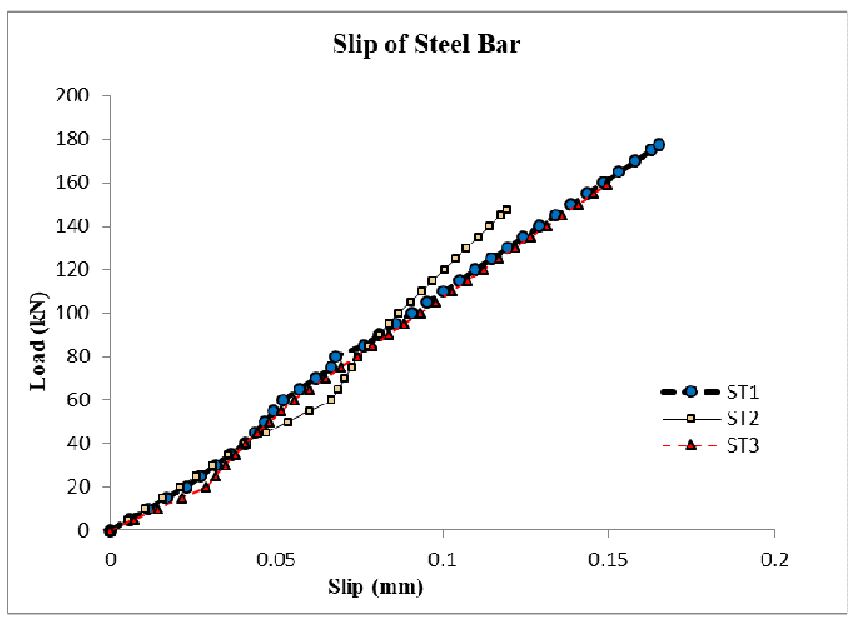

Fig. 16 Load-Slip on Steel Reinforcement Concrete Relationships

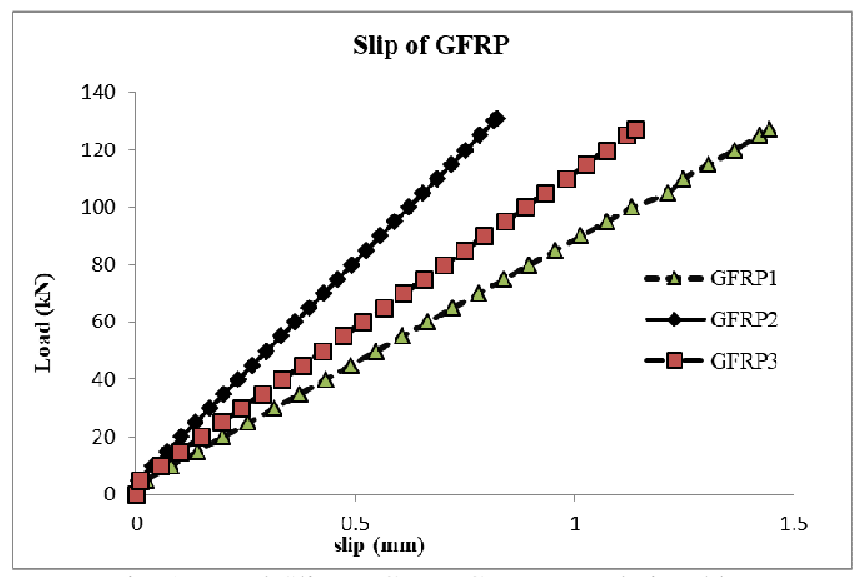

Fig. 17 Load-Slip on GFRP Concrete Relationships

\section{CONCLUSION}

The bond strength of GFRP reinforcement was $79.56 \%$ smaller than the bond strength of steel bar. The difference occurred in that bond strength was influenced by the rib on the surface of steel and GFRP reinforcements. The bond strength which exceeded the split force would cause a failure. The failure of all specimens was splitting failure.

\section{ACKNOWLEDGMENT}

We would like to thank P3M Politeknik Negeri Jakarta, PT Fyfe Indonesia, PT Pionir Beton Indonesia, PT MRT Jakarta, PUSKIM Bandung, and all parties who have helped this research.

\section{REFERENCES}

[1] S. J. A. Hosseini, A. B. A. Rahman, M. H. Osman, A. Saim, and A. Adnan, "Bond behavior of spirally confined splice of deformed bars in grout," Constr. Build. Mater., vol. 80, 2015.

[2] J. Michels, E. Martinelli, C. Czaderski, and M. Motavalli, "Prestressed CFRP Strips with Gradient Anchorage for Structural Concrete Retrofitting: Experiments and Numerical 
Modeling," Polymers (Basel)., vol. 6, no. 1, pp. 114-131, Jan. 2014.

[3] H. Wang, "Static and Fatigue Bond Characteristics of FRP Rebars Embedded in Fiber-reinforced Concrete Static and Fatigue Bond Characteristics," vol. 44, no. June, pp. 16051622,2010

[4] H. Wang, "An analytical study of bond strength associated with splitting of concrete cover An analytical study of bond strength associated with splitting of concrete cover," Eng. Struct., vol. 31, no. 4, pp. 968-975, 2009.

[5] Z. Wu, X. Zhang, J. Zheng, Y. Hu, and Q. Li, "Bond Behavior of Plain Round Bars Embedded in Concrete Subjected to Biaxial Lateral Tensile-Compressive Stresses," $J$. Struct. Eng., vol. 140, no. 4, pp. 15-25, 2014.

[6] Guohua Xing, Cheng Zhou, Tao $\mathrm{Wu}$, and Boquan Liu, "Experimental Study on Bond Behavior between Plain Reinforcing Bars and Concrete," Advances in Materials Science and Engineering, vol. 2015, Article ID 604280, 9 pages, 2015. doi: $10.1155 / 2015 / 604280$

[7] S. S. Mousavi, M. Dehestani, and S. M. Mousavi, "Bond strength and development length of glass fiber-reinforced polymer bar in unconfined self-consolidating concrete," $J$. Reinf. Plast. Compos., vol. 35, no. 11, pp. 924-941, 2016.

[8] M. Soleymani Ashtiani, R. P. Dhakal, A. N. Scott, and D. K. Bull, "Cyclic beam bending test for assessment of bond-slip behavior," Eng. Struct., vol. 56, 2013.

[9] C. W. Tang, "Uniaxial bond stress-slip behavior of reinforcing bars embedded in lightweight aggregate concrete," Struct. Eng. Mech., vol. 62, no. 5, pp. 651-661, 2017.

[10] G. Xing, C. Zhou, T. Wu, and B. Liu, "Experimental Study on Bond Behavior between Plain Reinforcing Bars and Concrete," Adv. Mater. Sci. Eng., vol. 2015, no. October, 2015.
[11] ASTM C234-91a (2000), Standard Test for Comparing Concrete on the Basis of Bond Developed with Reinforcing Steel. 2000.

[12] A. Belarbi and H. Wang, "Bond Durability of FRP Bars Embedded in Fiber-Reinforced Concrete," J. Compos. Constr., vol. 16, no. 4, pp. 371-380, 2012.

[13] A. Belarbi, F. ASCE, H. Wang, and M. Asce, "Bond Durability of FRP Bars Embedded in Fiber-Reinforced Concrete," J. Compos. Constr., vol. 16, no. August, pp. 371$380,2012$.

[14] H. Lesmana, Alfred; Tavio; Soegihardjo, "Desain Balok Jembatan Konvensional Dengan Penulangan Fiber Reinforced Polymer (FRP)," J. Tek. POMITS, pp. 1-6.

[15] E. G. Nawy, Reinforced Concrete by Nawy 6th Ed.pdf, Sixth Edit. New Jersey: Prentice-Hall, 2009.

[16] ASTM International, "Standard test method for tensile properties of plastics," ASTM Int., vol. 8, pp. 46-58, 2003.

[17] A. A. Shukri, K. M. Ud Darain, and M. Z. Jumaat, "The tension-stiffening contribution of NSM CFRP to the behavior of strengthened RC beams," Materials (Basel)., vol. 8, no. 7, pp. 4131-4146, 2015.

[18] N. G. Ivan Hollý, Juraj Bilcík, Ondrej Keseli, "Bond of GFRP Reinforcement with Concrete," Key Eng. Mater., vol. 691, no. May, p. 356, 2016.

[19] ASTM C234-91a (2000), Standard Test for Comparing Concrete on the Basis of Bond Developed with Reinforcing Steel. 2000.

[20] ASTM International, "Standard test method for tensile properties of plastics," ASTM Int., vol. 8, pp. 46-58, 2003.

[21] Firep Ribar. 2014. Glass Fiber Reinforced Polymer. Brosur. Japan: Firep Group. 